Cytogenet Genome Res 106:142A (2004)

DOI: $10.1159 / 000078573$

\section{Assignment of two isoforms of the AMP-activated protein kinase $\gamma$ subunits, PRKAG1 and PRKAG2 to porcine chromosomes 5 and 18, respectively by radiation hybrid panel mapping \\ G. Haberkern, P. Regenhard, G. Ottzen-Schirakow, E. Kalm, and C. Looft \\ Institute of Animal Breeding and Husbandry, \\ Christian-Albrechts-University, Kiel (Germany)}

Cytogenet Genome Res 106:142B (2004)

DOI: $10.1159 / 000078574$

\section{Assignment of the ovine uroporphyrinogen decarboxylase (UROD) gene to chromosome 1 p34 $\rightarrow$ p36 by fluorescence in situ hybridization}

R. Nezamzadeh, a J. Habermann, ${ }^{b}$ R. Fries, ${ }^{b}$ and B. Breniga ${ }^{a}$ Institute of Veterinary Medicine, Georg-August-University of Goettingen, Goettingen (Germany); ${ }^{\mathrm{b}}$ Chair for Animal Breeding and Genetics, WZW Technical University of Munich, Weihenstephan (Germany)
Cytogenet Genome Res 106:142C (2004) DOI: $10.1159 / 000078575$

\section{Assignment of the surfactant protein A gene (SFTPA) to bovine chromosome $28 q 1.8 \rightarrow$ q1.9 by radiation hybrid mapping}

M. Gjerstorff, a B. Dueholm, a C. Bendixen, ${ }^{b}$ U. Holmskov, a and S. Hansen ${ }^{a}$

${ }^{a}$ Department of Immunology and Microbiology, University of Southern Denmark, Odense (Denmark); ${ }^{b}$ Department of Animal Breeding and Genetics, Research Centre Foulum, Tjele (Denmark)

Cytogenet Genome Res 106:142D (2004)

DOI: $10.1159 / 000078565$

\section{Physical mapping and marker} development for the porcine glial cells missing homolog 1 (Drosophila) (GCM1) gene

A. Spötter, C. Drögemüller, H. Kuiper, H. Hamann, and O. Distl Institute of Animal Breeding and Genetics, School of Veterinary Medicine Hannover, Hannover (Germany)

Cytogenet Genome Res 106:142E (2004) DOI: $10.1159 / 000078566$

Mapping of three porcine 20S proteasome genes using the IMpRH panel

X. Wu, ${ }^{\text {a M. Yu, }}{ }^{\text {a B. Liu, a M. Yerle, }}{ }^{\text {b S.H. Zhao, }}{ }^{\text {a }}$ Y.F. Wang, ${ }^{\text {a B. }}$ Fan a and K. $\mathrm{Li}^{\mathrm{a}}$

${ }^{a}$ Laboratory of Molecular Biology and Animal Breeding, School of Animal Science and Technology, Huazhong Agricultural University,

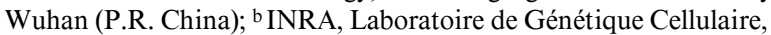

Castanet-Tolosan (France) 